organisation which guides nationwide swimming instruction and lifesaving issues. FSL co-operates actively with public authorities in water safety issues.

Methods The Master's Degree thesis examined, through 160 near-drowning experiences, what happens to people in drowning situations. The gathered information was then compared to the water safety instructions given by FSL. Thus, the main aim of the study was to utilise the gathered information in the future water safety instructions given by FSL. Another aim was to search for effective ways to enhance drowning-prevention interventions.

Results Even when instructions for water safety are essentially good, people find it difficult to follow them. In a drowning situation there is often an absence of rational thinking when one's life is in danger. This means that it is extremely important to avoid being alone both when in and by the water. Both, the concept of parental responsibility and the constant monitoring of one's own children in and near water, vary greatly and are lacking.

Conclusions Water safety education is challenging. The drowning experience is always tied to a situation, where many things and coincidences affect it. People are not able to follow water safety instructions, neither in a preventative sense nor in the actual emergency situation. People trust their own "common sense" and this isn 't always a good thing. Even though the water safety tips are simple, they are not always put into practice in water.

\section{ESTABLISHING AN EVIDENCE BASE FOR DROWNING INTERVENTIONS IN THE REPUBLIC OF IRELAND}

${ }^{1}$ Aoife Kervick, ${ }^{2}$ Dani Dix, ${ }^{2}$ Thomas Walters, ${ }^{3}$ Roger Sweeney, ${ }^{1}$ Kiran Sarma. ${ }^{1}$ National University of Ireland, Galway, Ireland; ${ }^{2}$ Royal National Lifeboat Institution, United Kingdom; Irish Water Safety, Ireland

\subsection{6/injuryprev-2016-042156.831}

Background Drowning fatalities are a significant global health problem, with close to 400,000 people drowning each year worldwide. In the Republic of Ireland (ROI), approximately 135 people drown per annum, the majority of which are preventable incidents. International best practice calls for the use of evidencebased interventions to prevent drowning deaths. This research project aimed to improve the current scope and quality of drowning fatalities data available in Ireland, to facilitate optimal intervention design, and ultimately reduce drowning deaths.

Methods This project consisted of three main stages. The first involved a scoping exercise designed to identify the extent of missing drowning fatality data, achieved by comparing source records for 2012-2013 held by the statutory body Irish Water Safety with official Irish death statistics. Means of increasing fatalities coverage were then investigated, including assessing media reports. Second, new drowning data taxonomies to enhance the detail of the data captured following a fatality were designed, and evaluated during an expert stakeholder workshop. Third, a novel Irish drowning fatalities database using these taxonomies was created for future use.

Results Findings from the first stage indicated that records for $62 \%$ of drowning fatalities that occurred in Ireland during 20122013 were missing. The use of additional drowning data sources, including access to complimentary fatality records and media reports increased coverage considerably for this period. The proposed taxonomies were evaluated favourably during the workshop, and database uptake has been promising.

Conclusions Drowning fatality data quality and coverage in the ROI can be improved. The new database and taxonomies will serve as valuable future resources, with the potential to reliably inform prevention strategies and intervention design.

\section{EXAMINING COASTAL DROWNING FATALITIES IN THE REPUBLIC OF IRELAND, 2010-2013}

${ }^{1}$ Aoife Kervick, ${ }^{2}$ Dani Dix, ${ }^{2}$ Thomas Walters, ${ }^{3}$ Roger Sweeney, ${ }^{1}$ Kiran Sarma. ${ }^{1}$ National University of Ireland, Galway, Ireland; ${ }^{2}$ Royal National Lifeboat Institution, UK; ${ }^{3}$ Irish Water Safety, Ireland

\subsection{6/injuryprev-2016-042156.832}

Background On average, 135 people drown in the Republic of Ireland (ROI) every year. There is growing recognition that coastal drowning fatalities in particular are a significant health concern.

In order to inform the design of targeted prevention strategies for coastal areas in the ROI, this research study sought to enhance and augment current coastal drowning fatality records, and produce detailed statistical estimates in relation to these deaths.

Methods A coastal drowning dataset was compiled. To enhance data records, complimentary sources were investigated, including data from the Royal National Lifeboat Institution (RNLI) and media reports. Unique coastal fatality cases were identified by location, name of victim (where possible), date of incident, and/ or other identifiers as needed (such as age, gender). The fatality cause was then classified (e.g. due to accident, suspected selfharm etc.), and data analysed.

Results Complimentary data sources improved the scope of initial records from documenting 70 coastal drowning fatalities, to records for 198 that occurred during this time period. Overall, coastal drowning deaths accounted for approximately $39 \%$ of all drowning fatalities that occurred in the ROI during 2010-2013. The majority of these were accidental deaths (48\%), unspecified incidents $(26.3 \%)$, due to suspected self-harm $(24.7 \%)$, natural causes $(0.5 \%)$ or assault $(0.5 \%)$. Where gender and age were documented, it was found that males comprised $82 \%$ of fatalities $(n=124)$, and that those aged between 30-69 years accounted for $81 \%(n=104)$ of coastal drowning deaths.

Conclusions Coastal drowning fatalities accounted for approximately $40 \%$ of all drownings that occurred in the ROI during 2010-2013. Findings suggest that coastal drowning interventions should focus on targeting males, and those above 30 years of age.

\section{DROWNING PREVENTION AND LIFE SAVING PROGRAM 2012 THAILAND}

${ }^{1}$ Emma Jonsson, ${ }^{2}$ Terese Finnander. ${ }^{1}$ University of Skövde, Sweden; ${ }^{2}$ University of Skövde, Sweden

10.1136/injuryprev-2016-042156.833

Background Worldwide, drowning is the third leading cause of death among children. In Asia it is the first leading cause of death and a major public health threat. The objective of this paper was to develop a drowning prevention program including swimming training, CPR and lifesaving methods for children and to evaluate it. This intervention was provided and evaluated in Thailand where drowning is the first leading cause of death among children.

Methods Thailand where drowning is the first leading cause of death among children. The study used observations, quantitative and qualitative methods. In total 20 children in the age of seven 
to ten, from Nan Province in northern Thailand were participating.

Results The result of this intervention is that the children are highly capable to learn swimming, CPR and lifesaving activities within 10 days. Out of 20 participants all have successfully completed the swimming, CPR and lifesaving programs.

Conclusions The conclusion of this intervention study can be sum up by both the interventions result, the questionnaires and the independent evaluators is that swimming program as this one is highly needed for saving lives. Support from the local as well as the central authority is also needed.

Therefore such swimming program shows the importance of swimming knowledge and water security to prevent drowning in near future.

\section{FEASIBILITY OF TEACHING FIRST RESPONSE TO CHILDREN BELOW 10 YEARS IN RURAL BANGLADESH}

${ }^{1}$ Mahruba Khanam, ${ }^{1}$ Aminur Rahman, 'Shashwati Sarkar, ${ }^{2}$ Steve Beerman, ${ }^{3}$ Justin Scarr, ${ }^{4}$ Michael Linnan. ${ }^{1}$ International Drowning Research Centre - Bangladesh (IDRC-B) of Centre for Injury Prevention and Research, Bangladesh (CIPRB), Dhaka, Bangladesh; ' University of British Columbia, Vancouver, Canada; ${ }^{3}$ Royal Life Saving Society Australia, Sydney, Australia; ${ }^{4}$ The Alliance for Safe Children, Atlanta, USA

\subsection{6/injuryprev-2016-042156.834}

Background One research activity established a community-based first response system including CPR. Participants were aged 10 years and over and each age group demonstrated that they could successfully learn CPR and retain the skills over time. Another research activity involved teaching children 4 years old and over basic swimming skills and safe rescue. Follow-up research on the children showed that many conducted rescues. The average age of rescuer and rescuee was 9 years and 3 years respectively. Some rescues were not successful as the victim lacked a pulse and respiration. This demonstrated a need for children younger than 10 years old to be able to resuscitate young children. The objective of the study was to develop a group of young community first responders between the ages of 7 and 9 years to provide first aid and CPR in order to demonstrate whether first responders in that age group were able to provide emergency response when required

Methods Ten community swimming instructors (CSIs) were trained to teach first aid and CPR to children 7-9 years. The CSIs participated in a two-day intensive training-of-trainers activity. A standard first aid course including CPR was taught to the children using child manikins following swim training in the SwimSafe program.

Results A total of 811 children participated in the training programme. The male:female proportion was 51.2 percent and 48.8 percent. A total of 82.5 percent of participants passed the first aid and CPR certification process. Passing rates were similar for both sexes and the highest passing rates were noted in 7 year old boys (85.0 percent) and girls (87.0 percent).

Conclusion Children aged 7-9 years old can learn the skills of first aid and CPR. Further research is needed to demonstrate that skills are retained over time and that once trained, these young children can provide successful first response activities in emergencies that include CPR.

\section{WHAT'S THE REPORTING STATUS OF CHILD DROWNING AND NEAR DROWNING: FINDINGS FROM 10 DISTRICT'S GOVERNMENT HEALTH FACILITIES OF BANGLADESH}

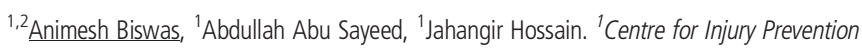
and Research, Bangladesh (CIPRB); ${ }^{2}$ Centre for Injury Prevention and Safety Promotion, School of Health and Medical Sciences, Örebro University, Sweden

\subsection{6/injuryprev-2016-042156.835}

Background Drowning is the leading killer of children globally, especially in developing countries. In Bangladesh, drowning is the cause of death in under five. Bangladesh health and injury survey published in 2004, shown that every year around 18000 children die due to drowning. While estimated magnitude if drowning deaths are still so high from other research findings in Bangladesh. Drowning death in majority cases are under reported, deaths are not properly registering in national Management Informational System (MIS) of Directorate General of Health Services (DGHS). The study is to explore district government hospital records on drowning deaths and near drowning treated in the facilities. The study also identified why deaths/near deaths due to drowning were low reported.

Methodology We have purposively selected 10 districts, in where 10 district hospitals and 69 Upazila Health complex (Primary health care centres at the sub-district level). Retrospective data was collected from the facilities from January - December 2014 for reported drowning death or come to hospital with near drowning. We also conducted 20 short interviews with the health care providers at the district and upazila health facilities.

Results A total 246 drowning deaths were reported in 9 districts during 2014, one district didn't recorded any deaths in children. Reported drowning rate was found 3.35/100,000, whereas, another 159 near drowning children come to hospital for treatment and has recorded in hospital register. Near drowning rate was found 2.0/100, 000. Health care providers at districts and upazila facilities mentioned that drowning cases rarely come to hospital and the community didn't feel it's necessary to report or bring the drown child to hospital. Like this, they also mentioned, near drowning case were found to be mostly treated locally, they don't bring their children to the facilities.

Conclusions Present findings from the hospital record shown that there are serious under reporting of drowning and near drowning cases. Bangladesh health and injury survey shown drowning rate $28.6 / 100,000$ in children and near drowning is $118 / 100,000$ which are much higher. To understand the real burden of the injury and survival of the children, it's extremely essential to have a comprehensive data record on drowning nationally.

\section{Fire Safety}

\section{Post Tue 2.24}

\section{AN EXPLORATION OF PAEDIATRIC BURN INJURIES, ASSOCIATED WITH COOKING, IN RURAL AND PERI- URBAN MALAWI}

Maria Beard, Michael Watson, Michael Clifford. The University of Nottingham, UK

10.1136/injuryprev-2016-042156.836

Background Burn injury rates are especially high in Africa where exposure to unsafe cooking appliances and open fires pose 